\title{
AOR
}

Selected Papers of \#AolR2020:

The $21^{\text {st }}$ Annual Conference of the

Association of Internet Researchers

Virtual Event / 27-31 October 2020

\section{SOCIAL MEDIA INSECURITIES IN EVERYDAY LIFE AMONG YOUNG ADULTS - AN ETHNOGRAPHY OF ANONYMOUS JODEL DISCLOSURES}

Malene Charlotte Larsen

Aalborg University

This paper analyzes what makes young adults feel insecure when they use social media in everyday life as a means to socialize and connect with peers. The analysis is based on a two-year online ethnography (Hine, 2015) conducted on Jodel, an anonymous location based social media app popular among young adults across Europe. The paper focuses on Jodel users' anonymous disclosures about their social media related insecurities - shedding light on discourses related to social media practices that are often hidden or neglected in interview studies.

The analysis finds that it is often the affordances of the social media platforms (Bucher \& Helmond, 2018) or changes in the design of apps such as Snapchat, Instagram or Tinder that lead to feelings of insecurity or uncertainty in relational maintenance or in the forming of new relationships. Thus, the codes of everyday actions become unclear and different expectations as to the affordances of social media platforms result in diffuse interaction orders (Goffman, 1983) in various situations. Put in other words: Because of the platforms, young adults sometimes find it difficult to know why peers behave like they do online resulting in unfounded worries and feelings of insecurity.

\section{Background and Jodel as ethnographic site}

The ethnographic study was carried out from $2017-2019$ on the anonymous location based social media app Jodel that is "aimed at encouraging people to interact with each other locally in meaningful ways" (Jodel, 2020). Originally, Jodel was designed for anonymous on-campus communication, but has gained popularity among various groups of young adults between the age of 18 and 30. Updates and photos are shared anonymously, and the user has no public profile that link individual posts together. The app is moderated by users with a large amount of Karma points. Karma points are designed to shows the user's positive impact on the app. One collects karma by "writing

Suggested Citation (APA): Larsen, M. C. (2020, October). Social media insecurities in everyday life among young adults - an ethnography of anonymous Jodel disclosures. Paper presented at AolR 2020: The $21^{\text {th }}$ Annual Conference of the Association of Internet Researchers. Virtual Event: AolR. Retrieved from http://spir.aoir.org. 
cool and funny posts, helping other Jodelers and contributing to the overall positive atmosphere" (Jodel, 2020).

With the app being location based, the participant observations were conducted among posts and replies uploaded from people within a range of 10 kilometers from the author's hometown, a larger Danish university town. At the outset, the ethnographic study had an interest in the combination of anonymity and hyperlocal communication: What does it mean to communicate anonymously with people geographically close to you? What do young adults reveal about themselves when they know that posts are seen by people within $1 \mathrm{~km}$ from their psychical location? The observations unveiled that - besides trivial updates about everyday life, jokes and photos of food and cats etc. - young adults often use the app as a venue for complaints or expressions of insecurities related to other social media platforms such as Snapchat, Instagram and Tinder. The ethnographic study ended up focusing on those disclosures. As ethnographic site Jodel then became a window into some of the uncertainties young adults face when they use social media as part of everyday life, e.g. worries about not receiving "enough" likes, insecurities related to Snapchat points or ephemeral interaction in general (Bayer et. al., 2016; Kofoed \& Larsen, 2016).

The author observed and participated on the app daily for a period of two years, wrote field notes, took screenshots and organized relevant disclosures. As a follow up study, individual interviews were conducted, both anonymously via chat and in physical settings, asking informants about the central themes from the ethnographic study.

\section{Theoretical background}

The paper is situated within the field of discourse studies with Nexus Analysis (Scollon, 2001; Scollon \& Scollon, 2004) as the theoretical approach. Nexus analysis distinguishes itself from other discourse analytic approaches by focusing on central mediated actions within a loosely tied 'nexus of practice'. The term refers to the social field where humans, discourses and cultural artefacts intersect and result in social action. Thus, interactions on social media platforms such as Jodel can be analyzed from a nexus analytical perspective (Larsen \& Raudaskoski, 2018). The objective of the ethnographic engagement is then to find central mediated actions and cycles of discourses within the overall nexus of practice and analyze them as parts of a sociohistorical process.

Here, it is important to understand how mediated actions of a specific site of engagement relate to other sites, practices and discourses. Circulating discourses intersect with cultural and material artifacts, specific forms of encounters between people (the interaction order) and the social identities and relationships played out (Larsen \& Raudaskoski, 2018; Scollon \& Scollon, 2004).

\section{Analytical themes}

The analysis is divided into three themes covering different cycles of discourse and thereby different aspects of social media's role in everyday life: 1) Ephemeral matching, focusing on social media dating apps (Carpenter \& McEwan, 2016) and their role in forming new relationships, 2) Platformed sociality (van Dijck, 2013), focusing on how small changes in affordances and design affect social relations and rearrange typical 
interaction orders and 3) Algorithmic personalization, focusing on the role of algorithmic, personalized news feeds (Bucher, 2018) and one-click-interactions (Heyes et. al., 2016; Eranti \& Lonkila, 2015) such as liking practices.

During the analysis it is explored how different disclosures of feeling insecure can be linked to the design of different social media apps or recent design updates that have a somehow negative impact on the user's wellbeing and overall purpose of using the apps: Human connectedness.

\section{References}

Bayer, J. B., Ellison, N. B., Schoenebeck, S. Y., \& Falk, E. B. (2016). Sharing the small moments: Ephemeral social interaction on Snapchat. Information, Communication \& Society, 19(7), 956-977.

Bucher, T. (2018). If .... Then: Algorithmic power and politics. Oxford University Press.

Bucher, T., \& Helmond, A. (2018). The Affordances of Social Media Platforms. In J. Burgess, T. Poell, \& A. Marwick (Eds.), The SAGE Handbook of Social Media. Sage Publications, pp. 233-253.

Carpenter, C. J., \& McEwan, B. (2016). The players of micro-dating: Individual and gender differences in goal orientations toward micro-dating apps. First Monday, 21(5).

Eranti, V., \& Lonkila, M. (2015). The social significance of the Facebook Like button. First Monday, 20(6).

Goffman, E. (1983). The Interaction Order: American Sociological Association, 1982 Presidential Address. American Sociological Review, 48(1), 1-17.

Jodel (2020). Jodel support: https://jodel.zendesk.com/hc/en-us

Hayes, R. A., Carr, C. T., \& Wohn, D. Y. (2016). One Click, Many Meanings: Interpreting Paralinguistic Digital Affordances in Social Media. Journal of Broadcasting \& Electronic Media, 60(1), 171-187.

Hine, C. (2015). Ethnography for the Internet: Embedded, Embodied and Everyday. London: Bloomsbury Publishing.

Kofoed, J., \& Larsen, M. C. (2016). A snap of intimacy: Photo-sharing practices among young people on social media. First Monday; Volume 21, Number 11 - 7 November 2016.

Larsen, M. C., \& Raudaskoski, P. L. (2018). Nexus Analysis as a Framework for Internet Studies. In J. Hunsinger, L. Klastrup, \& M. Allen (Eds.), International Handbook for Internet Research (Vol. 2) 
Scollon, R. (2001). Mediated discourse: The Nexus of Practice. London; New York: Routledge.

Scollon, R., \& Scollon, S. W. (2004). Nexus Analysis: Discourse and the Emerging Internet. London; New York: Routledge.

van Dijck, J. (2013). The culture of connectivity : a critical history of social media. New York: Oxford University Press. 